\title{
Resistance to visceral leishmaniasis is severely compromised in mice deficient of bradykinin B2-receptors
}

\author{
Dirlei Nico ${ }^{1}$, Daniel Ferreira Feijó ${ }^{1}$, Naiara Maran ${ }^{1}$, Alexandre Morrot ${ }^{1}$, Julio Scharfstein ${ }^{2}$, Marcos Palatnik $^{3}$ and \\ Clarisa Beatriz Palatnik-de-Sousa ${ }^{{ }^{*}}$
}

\begin{abstract}
Background: Kinins liberated from plasma-borne kininogens, are potent innate stimulatory signals. We evaluated whether resistance to infection by Leishmania (L.) chagasi depends on activation of G-protein coupled bradykinin B2 receptors (B2R).

Findings: $\mathrm{B} 2 \mathrm{R}^{-/-} \mathrm{C} 57 \mathrm{BL} / 6$ knock-out (KOB2) and B2R ${ }^{+/+}$C57BL/6-wild type control mice (C57) were infected with amastigotes of Leishmania (L.) chagasi. Thirty days after infection, the KOB2 mice showed 14\% and 32\% relative increases of liver $(p<0.017)$ and spleen weights $(p<0.050)$, respectively, whereas liver parasite load increased $65 \%$ $(p<0.011)$ in relation to wild type mice. The relative weight increases of liver and spleen and the parasite load were positively correlated ( $R=0.6911 ; p<0.007$ to $R=0.7629 ; p<0.001$, respectively). Conversely, we found a negative correlation between the increased liver relative weight and the weakened DTH response (a strong correlate to protection or natural resistance to $\mathrm{VL}$ ) or the decreased levels of $\lg \mathrm{G} 2 \mathrm{~b}$ antibodies to leishmanial antigen. Finally, we also found that IFN- $\gamma$ secretion by splenocytes, an adaptive response that was significantly decreased in KOB2 mice ( $p<0.002)$, was (i) negatively correlated to the increase in liver LDU $(R=-0.6684 ; p=0.035)$ and liver/body relative weight ( $R=-0.6946 ; p=0.026$ ) and (ii) positively correlated to serum lgG2b levels $(R=0.8817 ; p=0.001)$.

Conclusions: We found that mice lacking B2R display increased susceptibility to the infection by Leishmania (L.) chagasi. Our findings suggest that activation of the bradykinin/B2R pathway contributes to development of host resistance to visceral leishmaniasis.
\end{abstract}

Keywords: B2 kinin receptor, Visceral leishmaniasis, Leishmania (L.) donovani, Leishmania (L.) chagasi, Susceptibility, Resistance

\section{Findings}

$\mathrm{VL}$ is a chronic and vector-borne potentially fatal parasitic disease caused by the Leishmania (L.) donovani / Leishmania (L.) infantum / Leishmania (L.) chagasi complex which is associated to fever, malaise, anaemia, caquexia, fatigue, enlargement of the liver, spleen and lymph nodes, hypergammaglobulinemia and to the progressive suppression of cellular immunity [1,2]. Anti-parasite immune response against the parasite is still present at early infection and recovery after cure subsequent to chemotherapy; this

\footnotetext{
* Correspondence: immgcpa@micro.ufrj.br

'Instituto de Microbiologia Paulo de Góes, CCS, Universidade Federal do Rio de Janeiro (UFRJ), Avda. Carlos Chagas 373. Cidade Universitária, Ilha do

Fundão, Rio de Janeiro Caixa Postal 68040, 21941-902, Brazil

Full list of author information is available at the end of the article
}

can easily been assessed by the determination of the delayed type hypersensitivity following injection of a leishmanial antigen [3-5]. The variable degrees of susceptibility or natural resistance to VL have been the focus of intense studies in the mice and dog models [6,7] and in humans [8] since the 70's. A genetic basis for the susceptibility to VL was described in mice, dogs and humans [7,9-11]. It is well known that innate immunity plays a pivotal role in host resistance to VL. There is now awareness that alert signals expressed by pathogens and/or generated by injured tissues might link the innate system to adaptive immunity. Tissue injury can lead to bradykinin or Lysylbradykinin excision from high and low molecular weight kininogens by the respective action of the serine proteases,

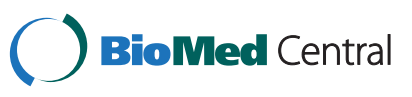


plasma and tissue kallikrein [12]. Once liberated, the short-lived kinins induce inflammatory responses (e.g. increased blood flow, oedema formation, vasodilatation and pain sensation) through the activation of two distinct subtypes of G-protein coupled bradykinin receptors (BR). One of these, $B_{2} R$, is constitutively expressed by a broad range of host cell types, e.g., endothelial cells, epithelial cells neurons and dendritic cells (DCs) [12,13]. In mice infected subcutaneously by Trypanosoma cruzi, immature CD11c ${ }^{+}$DCs detect the presence of kinin peptides liberated in peripheral sites of infection through the signalling of $\mathrm{B}_{2} \mathrm{R}$ [14]. Upon maturation, the antigen-bearing $\mathrm{B}_{2} \mathrm{R}^{+/+}$ DCs emigrate to secondary lymphoid tissues of chagasic mice where they prime naive $\mathrm{T}$ cells while steering Th1 polarization via the IL-12-dependent pathway [13-15]. Using a systemic model of T.cruzi infection, Monteiro et al. showed that $\mathrm{B}_{2} \mathrm{R}^{-/-}$mice succumb to acute parasite challenge [13]. After showing that $\mathrm{B}_{2} \mathrm{R}^{-/-}$chagasic mice failed to optimally develop type- $1 \mathrm{~T}$ cell effectors, these authors showed evidence that their susceptible phenotype is a consequence of impaired maturation of splenic $\mathrm{B}_{2} \mathrm{R}^{-/-}$ DCs [13]. Interestingly, in Balb/c infected (mucosally) with the periodontal bacteria Porphyromonas gingivalis, the activation of the kinin/B2R pathway generated IL-17 and IFN- $\gamma$ - producing $\mathrm{T}$ cells whereas infected C57BL/6 mice exclusively generated IFN- $\gamma$-producing $\mathrm{T}$ cells, (likewise in B2R-dependent manner) [16].

Regarding VL, in vivo studies in mice and hamsters showed that Leishmania (L.) donovani and Leishmania (L.) chagasi promastigotes evoke inflammatory oedema through the proteolytic release of kinins [17]. In addition, in vitro studies showed that activation of $\mathrm{B}_{2} \mathrm{R}$ enhance parasite uptake by splenic adherent cells while reducing amastigote outgrowth in inflammatory macrophages [17].

The Balb/c strain is extremely susceptible to tegumentary leishmaniasis infections by $L$. (L.) mexicana, $L$. (L.) major [18-21] and L. (L.) braziliensis [19] and the C57BL/6 strain is resistant to the infection by $L$. (L.) major [19-21] and L. (L.) braziliensis [19]. In the case of VL, on the other hand, the C57BL/6 strain was considered equally [18-20,22,23] or more susceptible [18] than the Balb/c strain, to the infections by L.(L.) donovani, L.(L.) infantum or L.(L.) chagasi, both developing high rates of parasites loads in liver during early acute infection. Furthermore, reflecting the genetic variability in the $\mathrm{H} 2$ locus, the Balb $\mathrm{H}-2^{\mathrm{d} / \mathrm{d}}$ haplotype is associated with persisting visceral leishmaniasis infection and the $\mathrm{H}-2^{\mathrm{b} / \mathrm{b}}$ haplotype with substantial recovery by day 130 after infection [18]. However, in spite of the impressive number of reports of VL studies performed in the Balb/c model [5,19-22], all the transgenic knock-out mice were developed within the C57BL/6 background and there are no B2R knock-out mice of Balb/c genetic background.
In this investigation we evaluated the potential role of the bradykinin receptor $\mathrm{B} 2 \mathrm{R}$ in resistance to $\mathrm{VL}$ using the C57BL/6 wild type mice and its BR2 knock-out mutant $\left(\mathrm{C} 57 \mathrm{BL} / 6 / \mathrm{BR}^{-/-}\right)$which shares the same $\mathrm{C} 57 \mathrm{BL} / 6$ genetic background.

\section{Methods}

C57Bl/6 B $\mathrm{R}^{-/-}$knock-out (KOB2) [24] and C57BL/6$\mathrm{B}^{2} \mathrm{R}^{+/+}$wild type control mice (C57) originated from breeding colonies kindly donated by Dr J.B. Pesquero (UNIFESP, São Paulo, Brazil) were maintained in our animal facilities (LAT- IBCCF, UFRJ). Deletion of the entire coding sequence of kinin B2 receptors was achieved according to the methodology previously described by Rupniak et al. [25]. Briefly, the generation of transgenic B2R mice was achieved by transfection of embryonic stem cells from J129 mice with a targeting vector designed to disrupt the B2 receptor gene. Then hybrid mice were obtained of the J129 and the C57 strain taking advantage the fertility capabilities of the C57 strain. Once the hybrid is obtained it is possible to generate a pure $\mathrm{C} 57 \mathrm{BL} / 6 \mathrm{~B} 2 \mathrm{R}^{-1-}$ strain through repeated backcrossing with C57BL/6 [25]. All mouse studies followed the guidelines set by the National Institutes of Health, USA and the Institutional Animal Care and Use Committee approved the animal protocols (IBCCF, UFRJ, protocol IMPPG-007).

Female $\mathrm{C} 57 \mathrm{BL} / 6 \mathrm{BR}^{+/+}$and $\mathrm{B}_{2} \mathrm{R}^{-/-}$mice, 8-week-old, were challenged intravenously with $3 \times 10^{7} \mathrm{~L}$. (L.) chagasi amastigotes obtained from infected hamsters spleens. The strain used for challenge (IOC-L 3324) was originally isolated from the spleen of an infected dog of Andradina, São Paulo, Brazil and taxonomically characterized as Leishmania (L.) chagasi by the CLIOCWDCM 731 (Instituto Oswaldo Cruz Leishmania collection, Rio de Janeiro, Brazil). Thirty days after infection, mice were euthanized using gaseous Carbon Dioxide and the liver parasite load was evaluated in Giemsastained smears and expressed in LDU values (Leishman Donovan units of Stauber $=$ number of amastigotes per 1000 liver cell nuclei/mg of liver weight) [6,18]. The increases in liver and spleen/corporal relative weight were also recorded as clinical signs of VL.

The DTH against L. (L.) donovani lysate was measured in the footpads on day 28 after infection, as described earlier [26]. Briefly, mice were injected intradermally, in the right front footpad, with $10^{7}$ freeze-thawed stationary phase Leishmania (L.) donovani (LD 1S/MHOM/SD/ 00 -strain $1 \mathrm{~S}$ ) promastigotes in $0.1 \mathrm{ml}$ sterile saline solution. The contra-lateral footpad received $0.1 \mathrm{ml}$ saline, as control. Footpad thicknesses were measured with a Mitutoyo apparatus, at 0, 24 and $48 \mathrm{~h}$ after injection. At each measurement, the values of the saline control were subtracted from the reaction due to the Leishmania 
antigen. Previous experiments performed in mice and CB hamsters demonstrated that the saline treated footpads returned to base levels $24 \mathrm{~h}$ after inoculation [26].

Serum antibody responses were monitored by an enzyme-linked immunosorbent assay (ELISA) using as antigen the recombinant Nucleoside hydrolase (NH36) of Leishmania (L.) donovani [27] or the freeze and thawed lysate of stationary phase promastigotes of Leishmania (L.) chagasi (LIOC 579). The NH36 protein cloned into the pET28b expression system was expressed in E. coli Bl21DE3 cells and purified in a NiNTA column (Qiagen) [27]. Thirty days after infection with $L$. (L.) chagasi, sera were collected and the ELISA assay performed by using $2 \mu \mathrm{g}$ of recombinant $\mathrm{NH} 36$ or promastigote lysate per well and goat anti-mouse IgG1 and IgG2b-horseradish peroxidase conjugate (Southern Biotechnology Associates, Birmingham, Ala.) at 1:1,000 dilution in blocking buffer. The reaction was developed with $o$-phenylenediamine (Sigma), interrupted with $1 \mathrm{~N}$ sulphuric acid, and read at $492 \eta \mathrm{m}$. Sera were analyzed at a $1 / 100$ dilution in triplicate. Positive and negative control sera were included in each test.

Furthermore, for the assay of IFN- $\gamma$ secretion we used $10^{6}$ splenocytes after 5 days of in vitro culturing at $37^{\circ} \mathrm{C}$ and 5\% CO2 in RPMI medium [27] and/or $10^{6}$ freezethawed stationary phase Leishmania (L.) chagasi (IOC L579) promastigotes in sterile saline solution obtained from infected and uninfected $\mathrm{C} 57$ and BOK2 mice. Secretions of IFN- $\gamma$ were evaluated in the supernatants with an enzyme-linked immunosorbent assay (ELISA) using purified antimouse IFN- $\gamma$ (clone R4-6A2; BD Bioscience), biotin-conjugated antimouse IFN- $\gamma$ (clone XMG1.2; BD Bioscience), streptavidin-alkaline phosphatase (BD Bioscience) and developed with ELISA Development Kit from R\&D System according to the manufacturer's instructions.

\section{Statistical analysis}

Means of variables were compared by Kruskall Wallis and Mann Whitney non-parametrical tests (Analyze-it). Correlation coefficient analysis was determined on a Pearson bivariate, two tailed test of significance (SPSS for windows). The values of $R^{2}$, which represents the fraction of the total variance in $\mathrm{Y}$ that can be explained by the variation in $\mathrm{X}$, were obtained using linear regression analysis (Analyze-it).

\section{Results}

In order to evaluate whether kinins may contribute to immune resistance to VL infection, wild type (C57) [22,23] and $\mathrm{B}_{2} \mathrm{R}^{-/-}$(KOB2) [13] mice were infected intravenously with Leishmania (L.) chagasi amastigotes. All animals were euthanized 30 days after infection in order to ascertain the clinical parameters that characterize advanced VL, e.g., by measuring liver and spleen/body relative weight, both of which are strong indicators of advanced VL [22,27]. Data shown in Figure 1 disclosed that the spleen $(\mathrm{p}=0.050)$ (Figure 1A) and liver/body relative weight (Figure 1B) $(\mathrm{p}=$ 0.017 ) were significantly increased in KOB2-infected mice as compared to the C57 mice. These results suggest that $\mathrm{B}_{2} \mathrm{R}$-receptor is implicated in the development of natural host resistance to experimental VL.

Next, we measured DTH responses to the promastigote leishmanial antigen to compare the efficiency of cellular immunity in mice infected with Leishmania (L.) chagasi [27]. Our data showed that the DTH response was significantly lower in the KOB2 mice as compared to response of the wild type infected animals (Figure $2 \mathrm{~A})(\mathrm{p}=0.003)$. These results suggest that the cellular immunity is

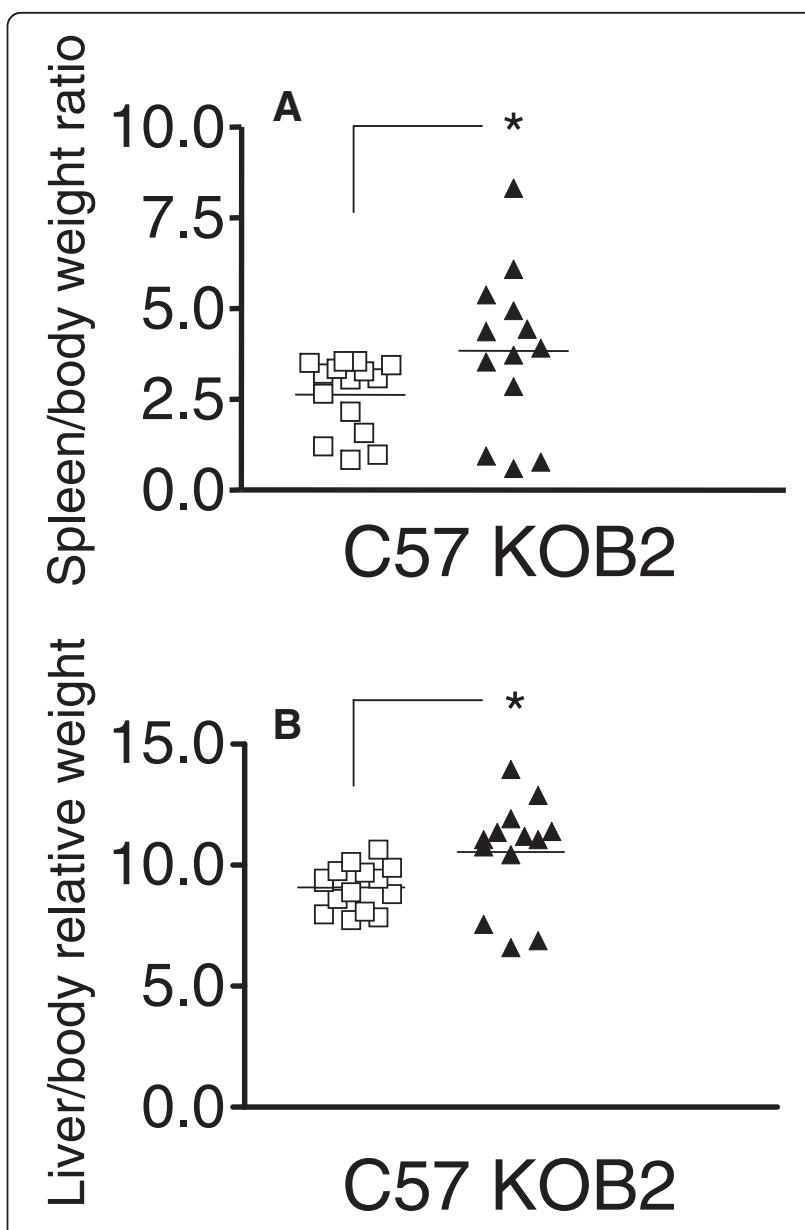

Figure 1 Spleen and liver/body relative weights are increased in $B_{2} R$-deficient mice infected with $L$. (L.) chagasi. The body weight was measured in grams at day 30 and the spleen (A) and liver / body relative weights (grams of organ weight $\times 100$ / grams of body weight) (B) were determined in $\mathrm{B}_{2} \mathrm{R}^{+/+}(\mathrm{C} 57)$ and $\mathrm{B}_{2} \mathrm{R}^{-/-}$mice (KOB2). Data represent the individual results for each group of mice $(n=3-5)$ of three independent experiments. Asterisks indicate significant differences between groups as disclosed by the Mann Whitney analysis. 


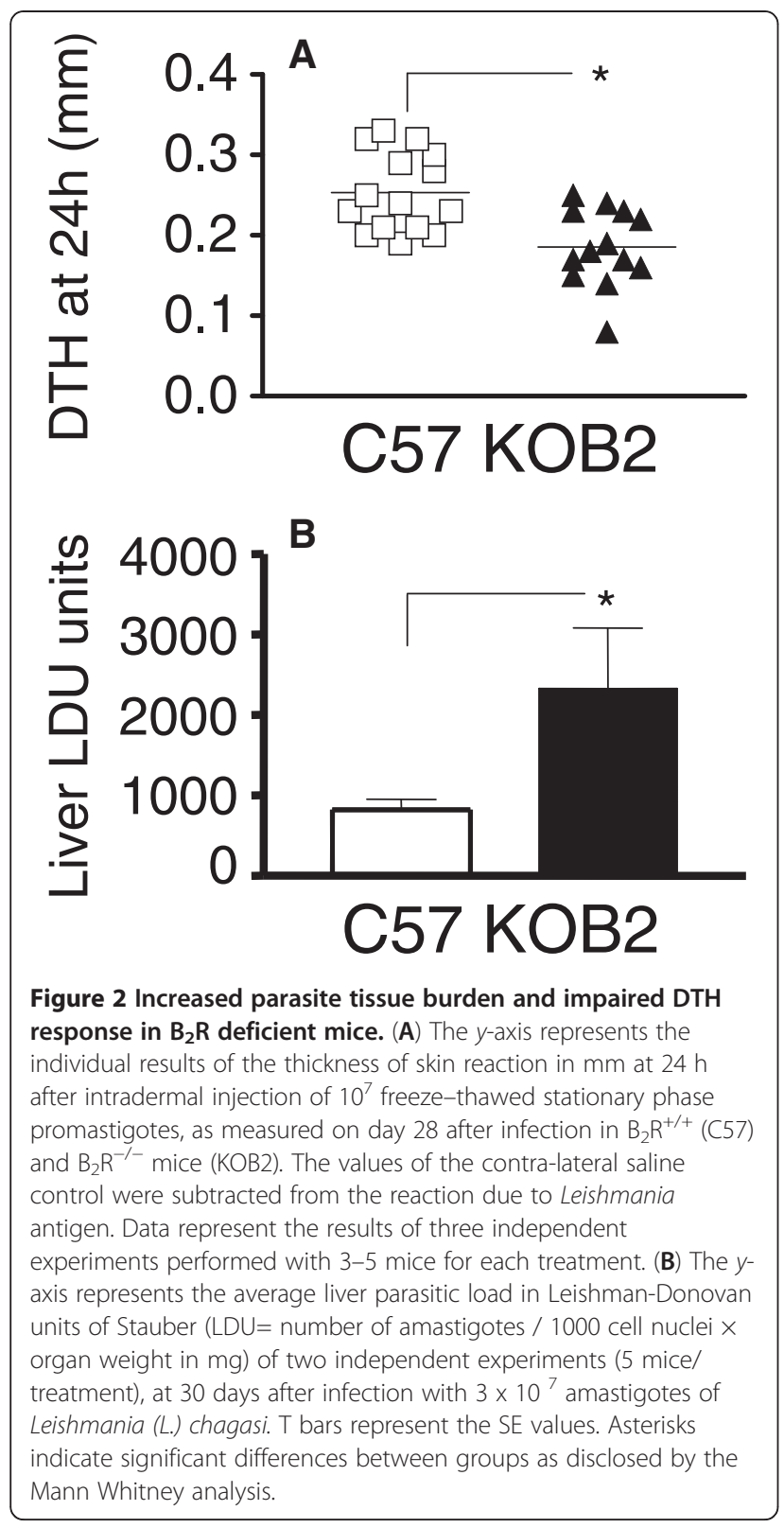

impaired in mice lacking $B_{2} R$, thus raising the possibility that activation of the kinin $/ B_{2} R$ pathway is required for optimal development of host resistance to LV. Consistent with this, KOB2 mice displayed an increase in the relative weight of spleen and liver (Figure $1 \mathrm{~A}$ and $\mathrm{B}$ ), whereas the DTH responses, as predicted, were impaired (Figure 2A). Noteworthy, the parasite load was significantly increased in the liver of the mutant mice $(65 \%$; $\mathrm{p}=0.011$; mean \pm $\mathrm{SE}=2327.64 \pm 795.41)$ over values of wild type mice $(818.73 \pm 139.55)$ (Figure 2B).

Although we have not characterized the mechanisms underlying the immune dysfunction of $\mathrm{B}_{2} \mathrm{R}^{-/-}$mice infected with Leishmania (L.) chagasi, studies in T. cruzi infected B2R-deficient mice, which also exhibited a susceptible phenotype, revealed that host resistance to systemic infection was impaired as a result of deficient DC responsiveness to endogenously released kinins $[13,15]$.

Our study showed that Leishmania (L.) chagasi infection of $\mathrm{B}_{2} \mathrm{R}^{-/-}$mice accurately reproduced the advanced VL clinical signs. For example, we found a highly significant positive correlation between the spleen/body $(R=$ $0.8600 ; \mathrm{p}<0.001)$, liver/ body relative weights $(\mathrm{R}=$ $0.6911 ; \mathrm{p}<0.007)$ and liver parasite load, all of which were increased (Figure 3A). Likewise, the increases in liver and spleen/body relative weights were also positively correlated $(\mathrm{R}=0.7629 ; \mathrm{p}<0.001)$. Furthermore, the decrease in DTH response against leishmanial antigen was negatively correlated to the increase in liver/ body relative weight $(\mathrm{R}=-0.5003 ; \mathrm{p}=0.025)$ (Figure $3 \mathrm{~B}$ ). Since DTH is a strong correlate of protection and required for optimal development of resistance to VL [27-30], we may infer that the impaired DTH observed in KOB2 mice is an expression of deficient cellular immunity.

As an adjuvant to conclude on the immunological status of the animals we also evaluated the anti-IgG1 and IgG2b antibodies in mouse sera. Our ELISA assays revealed that levels of IgG2b anti-NH36 antibodies in the infected C57 mice were significantly higher $(\mathrm{p}=$ 0.018 ) as compared to the KOB2 mice (Figure 4). The increase in IgG2b anti-NH36 antibodies and in DTH response were positively correlated $(\mathrm{R}=0.4587 ; \mathrm{p}=$ 0.042). Furthermore, similar to the DTH response (Figure $3 \mathrm{~B}$ ), the IgG2b increase was also negatively correlated to the increase in liver / body relative weight ( $R$ $=-0.5536 ; \mathrm{p}=0.011$ ) (Figure $3 \mathrm{C}$ ). When the ELISA assay was performed, using as antigen the total $L$. ( $L$.) chagasi lysate, the levels of IgG1 and IgG2b antibodies in the infected C57 mice were significantly higher ( $\mathrm{p}=$ 0.008 and $\mathrm{p}=0.032$, respectively) as compared to the KOB2 mice (Figure 4). The IgG1 or IgG2b antibodies themselves, on the other hand, showed no significant differences in their reactivity to NH36 or lysate, either for C57 or BOK2 mice. Furthermore, the anti-lysate IgG1 and IgG2b antibodies were positively correlated to the IFN- $\gamma$ secretion $(R=0.7063 ; p=0.022$ and $R=$ $0.8735 ; \mathrm{p}=0.001$, respectively) and negatively correlated to the parasite load in liver $(\mathrm{R}=-0.6560 ; \mathrm{p}=0.039$ and $\mathrm{R}=-0.6963 ; \mathrm{p}=0.025$, respectively). The anti-lysate IgG2b antibodies were also negatively correlated to the liver/ body relative weight $(\mathrm{R}=-0.6570 ; \mathrm{p}=0.039)$. Although the anti-NH36 or anti-L.(L.) chagasi lysate IgG2b antibodies are not protective by themselves, their increased levels serve as an indicator of a TH1 response, hence acting as a surrogate marker for natural resistance to VL [31]. The definition of an antigen that would discriminate antibodies generated during VL infection from antibodies induced by vaccination or natural resistance 

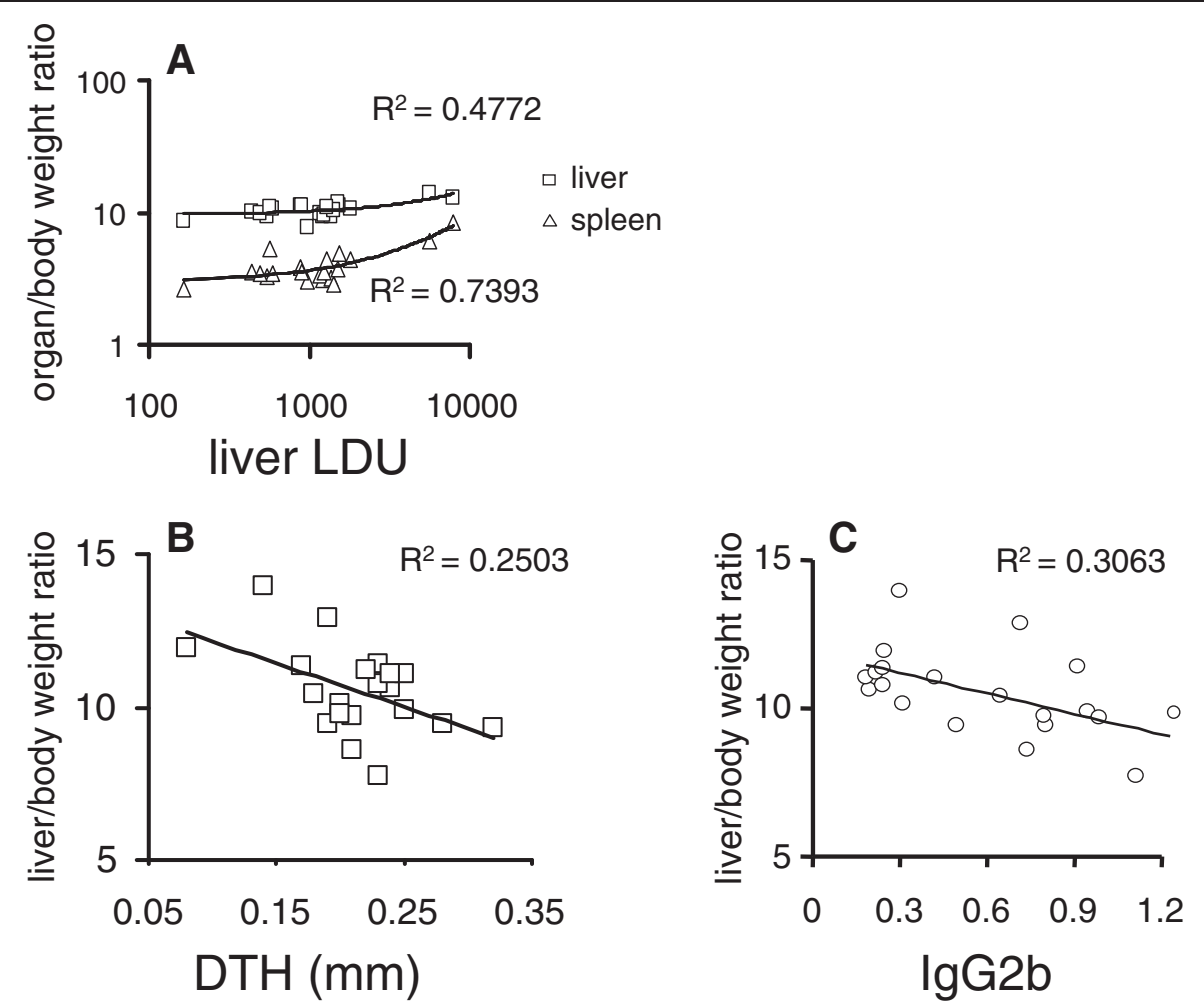

Figure 3 Correlation between the clinical signs of visceral leishmaniasis and the cellular versus antibody responses to leishmanial antigen. Data represented in bivariate graphics: $(\mathbf{A})$ the positive correlation between the individual increase of spleen and liver relative weights and the increase in liver parasite load; and (B) the negative correlation between the increase in liver relative weight and the decrease in DTH response to leishmanial antigen, and $(\mathbf{C})$ the increase in liver relative weight and the decrease in anti-NH36 IgG2b antibody response. The results were expressed on graphs as scattering of individual values. R-squared $\left(R^{2}\right)$ (coefficients of determination) estimates are shown on graphs. Trend lines were added.

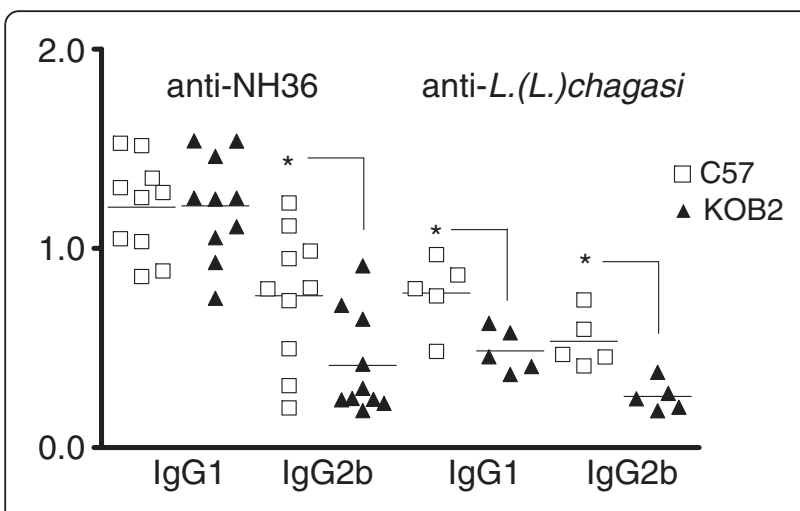

Figure 4 Evaluation of the $\lg \mathrm{G} 1$ and $\lg \mathrm{G} 2 \mathrm{~b}$ response in sera of mice deficient of $B_{2} R$. ELISA assay showing anti-Nucleoside hydrolase (NH36) and anti-L.(L.) chagasi promastigote lysate lgG1 and $\lg G 2 \mathrm{~b}$ antibodies in $\mathrm{B}_{2} \mathrm{R}^{+/+}$wild type (C57) and $\mathrm{B}_{2} \mathrm{R}^{-/-}$mice (KOB2) intravenously infected with $3 \times 10^{7}$ amastigotes of Leishmania. (L.) Chagasi. Results are shown as the individual absorbency values of 1/100 diluted sera obtained from two (NH36) or one (lysate) experiment with 5 mice per treatment in each experiment, at day 30 after infection. Asterisks indicate significant differences between groups as disclosed by the Mann Whitney analysis. has been the object of intense investigation, mainly in the canine model of VL [30,32]. The complex promastigote lysate or soluble antigen of $L$. (L.) infantum [33] or L. (L.) chagasi [34] did not discriminate between infected and vaccinated dogs. On the other hand Rafati et al., [33] showed that higher IgG2 than IgG1 titres were detected against the recombinant antigens but not against the $L$. (L.) infantum lysate. For these reasons, in this investigation we compared the reactivity to the $L$. (L.) chagasi promastigote lysate and to the NH36 Nucleoside hydrolase protein, which is a phylogenetic conserved marker of the Leishmania genus [35], a very important enzyme in the DNA metabolism and establishment of the parasite infection [36] and an antigenic marker of the canine patent disease [37]. Both antigens discriminated between the $\mathrm{C} 57$ and KOB2 groups regarding their IgG2b and only the lysate allowed detection differences in IgG1. The IgG2b antibodies are expected to be increased in mice that show either vaccine induced protection or natural resistance to Leishmania infection [27]. 

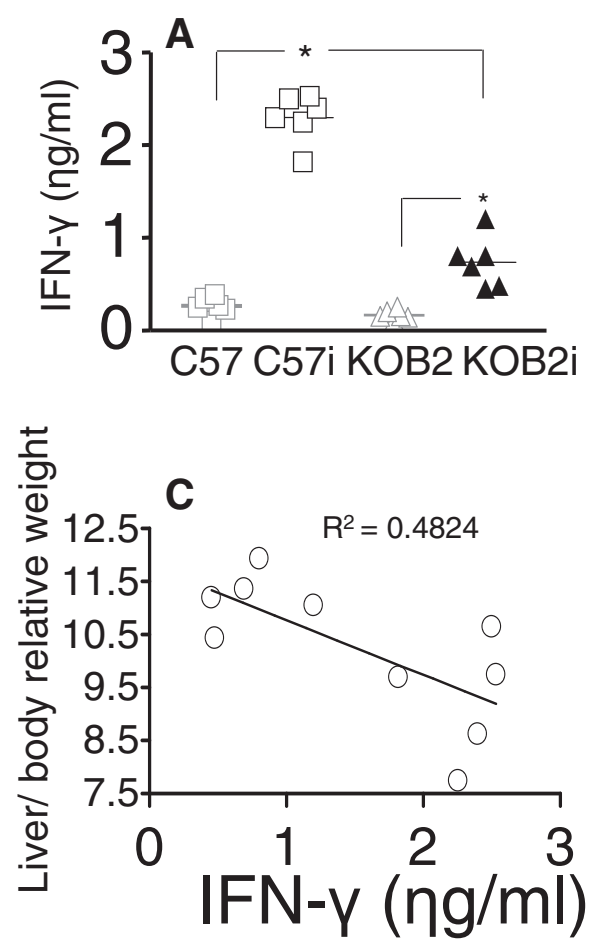

B
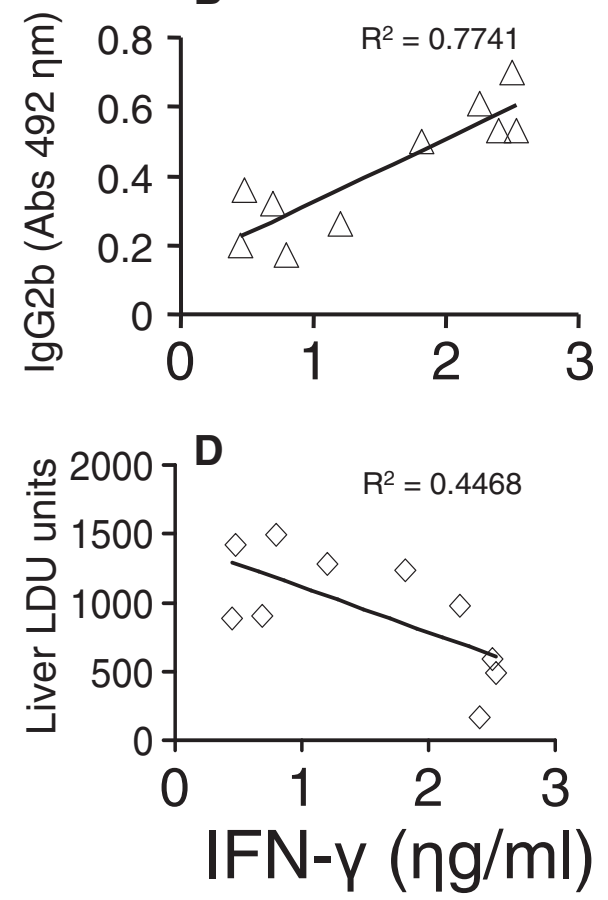

Figure 5 Assessment of the IFN- $\gamma$ cytokine secretion by splenocytes. IFN- $-\gamma$ was assayed in the supernatants of splenocytes of C57 and KOB2 infected mice and in uninfected C57 and KOB2 control mice after 5 days of in vitro culture with the freeze and thawed lysate of Leishmania (L.) chagasi promastigotes. Data correspond to individual results of one experiment with 6 mice of each group obtained after sacrifice. In graph $A$, horizontal full lines represent the mean values of C57 normal uninfected (C57), C57 infected (C57i), KOB2 normal uninfected (KOB2) and KOB2 infected (KOB2i) mice. ${ }^{*} p<0.05$ indicates significant differences to the saline control as disclosed by the Kruskall Wallis (KW) and Mann Whitney (MW) non-parametrical tests. The results were expressed on graphs as scattering of individual values. $R$ squared $\left(R^{2}\right)$ (coefficients of determination) estimates are shown on graphs. Trend lines were added.

Furthermore, the levels of IFN- $\gamma$ secreted into the supernatants of splenocytes were significantly lower $(\mathrm{p}=0.002)$ in the $\mathrm{KOB} 2$ infected mice $($ mean $=0.74 \eta \mathrm{g} / \mathrm{ml})$ than in the $\mathrm{C} 57$ infected mice $($ mean $=2.3 \eta \mathrm{g} / \mathrm{ml}$ ) (Figure 5). Both groups were different from their respective uninfected controls ( $p=0.002$ for each group) and neither the uninfected C57 or BOK2 mice secreted IFN- $\gamma(\mathrm{p}=0.093)$. As shown for the DTH and IgG2b response, the IFN- $\gamma$ in splenocyte supernatants was also a strong correlate for resistance to VL since its secretion was negatively correlated to the increase in liver LDU values $(\mathrm{R}=-0.6684$; $\mathrm{p}=$ $0.035)$ and liver/ body relative weight $(\mathrm{R}=-0.6946 ; \mathrm{p}=$ $0.026)$ and positively correlated to the IgG2b enhancement $(\mathrm{R}=0.8817 ; \mathrm{p}=0.001)$. In the C57 model of resistance to VL therefore, the IFN- $\gamma$ levels are also an indicator of a TH1 response to Leishmania (L.) chagasi, which is diminished in mice lacking the $\mathrm{B} 2$ receptor for bradykinin.

It might be argued that the quantification of the parasite load in bone marrow and spleen could also give a view of the influence of the bradykinin B2-receptor. Cotterell et al., [38] measured the parasite load in bone marrow of Balb/c mice infected with $2 \times 10^{7}$ amastigotes of $L$. (L.) donovani, through limiting dilution analysis or tissues smears and about 100 amastigotes were recorded/1000 bone marrow cell nuclei at day 28 after infection. The bone marrow parasite load was also studied by limiting dilution in Balb/c mice infected with $L$. (L.) infantum by Carrión et al., [39]. Limiting dilution differs from the direct microscopical counting of parasites in smears, in that the limiting dilution technique involves the culture amplification of the true number of parasites of the organ. In spite of this amplification, only 10 parasites were detected in bone marrow while 100,000 were detected in liver [39], showing that the sensitivity for parasite detection in bone marrow is very low, and any significant difference between the parasite load of C57 and KOB2 mice in this organ are not expected to be detected.

On the other hand, regarding the evaluation of the spleen parasite load in our model, we observed a mean average \pm SD of $91.11 \pm 29.13 \mathrm{LDU}$ units for C57BL/6 ${ }^{+/+}$ mice and $70.43 \pm 23.51$ for $\mathrm{C} 57 \mathrm{BL} / 6 \mathrm{BR} 2^{-1-}$ mice, with no significant differences between the two groups. Similar levels (75 LDUs) were reported by Cotterell et al., [38] in $\mathrm{Balb} / \mathrm{c}$ mice and much lower values were described by Ato et al., [23], who worked with C57BL/6 mice infected with 
a similar parasite inoculum $\left(2 \times 10^{7}\right.$ amastigotes of $L$.(L.) donovani) and obtained an average of only 2 LDU at 14 days, and $10 \mathrm{LDU}$ at 28 days after infection. This is probably due to the fact that in the classical model of mice VL acute infection after endovenous injection of the parasites, used by most authors [18,22,23,38,40], reviewed in [41] an early acute infection is detected in the liver and a later chronic infection in spleen, each one characterized by its own organ-specific immune responses $[23,40]$. We conclude that, in our model of acute VL infection, the best location to investigate the parasite load at day 30 after infection was the liver, where high parasite loads and significant differences between the $\mathrm{C} 57 \mathrm{BL} / 6 \mathrm{BR} 2^{-1-}$ and the C57BL/6 BR2 ${ }^{+/+}$wild type controls were found. Therefore, the liver gives the best view of the role of the BR2 receptor in resistance to VL at this earlier point of infection.

\section{Conclusions}

In summary, our results suggest that the natural resistance to the development of VL in C57BL/6 mice is at least partially dependent of the presence and functionality of the kinin $/ \mathrm{B}_{2} \mathrm{R}$ receptor pathway.

\section{Abbreviations}

VL: Visceral Leishmaniasis; B2R: Bradykinin B2 Receptors; C57 and B2R +/. C57BL/6 mice; KOB2 and B2R ${ }^{-1}$ : Bradykinin B2 receptors knock-out mice; DCs: Dendritic cells; DTH: Delayed type of hypersensitivity.

\section{Competing interests}

The authors declare that there is no conflict of interest regarding the present work and the sponsors had no role in study design, data collection and analysis, decision to publish, or preparation of the manuscript.

\section{Authors' contributions}

DN carried out most of the experimental procedures. DFF and NM carried out part of the experimental procedures. AM, JS, and CBPS conceived the research. MP and CBPS contributed with data analysis and revision of the manuscript. CBPS wrote the manuscript. JS reviewed and edited the final MS. All authors read and approved the final version of the manuscript.

\section{Acknowledgments}

We thank James Huntington for providing the use of the Analyze-it program. This work was supported by the Brazilian National Council of Scientific and Technological Development (CNPQ, PNPD-Post Doctorate and Productivity Fellowships and Grants) and by the Research Foundation of the State of Rio de Janeiro (FAPERJ, PNPD Post-Doctorate Fellowship and Grants).

\section{Author details \\ 'Instituto de Microbiologia Paulo de Góes, CCS, Universidade Federal do Rio de Janeiro (UFRJ), Avda. Carlos Chagas 373. Cidade Universitária, Ilha do Fundão, Rio de Janeiro Caixa Postal 68040, 21941-902, Brazil. ${ }^{2}$ Instituto de Biofísica Carlos Chagas Filho, Universidade Federal do Rio de Janeiro (UFRJ), Rio de Janeiro 21949-900, Brazil. ${ }^{3}$ Hospital Universitário Clementino Fraga Filho-Faculdade de Medicina, Universidade Federal do Rio de Janeiro (UFRJ), Rio de Janeiro CEP 21941-913, Brazil.}

Received: 29 June 2012 Accepted: 3 November 2012 Published: 14 November 2012

\section{References}

1. World Health Organization: Leishmaniasis: background information. http:// www.who.int/leishmaniasis/en/].

2. Palatnik-de-Sousa CB, Day MJ: One Health: the Global Challenge of Epidemic and Endemic Leishmaniasis. Parasites \& Vectors 2011, 4:197-207.
3. Baneth G, Koutinas AF, Solano-Gallego L, Bourdeau P, Ferrer L: Canine leishmaniosis - new concepts and insights on an expanding zoonosis: part one. Trends Parasitol 2008, 24:324-330.

4. Borja-Cabrera GP, Santos FN, Santos FB, Trivellato FA, Kawasaki JK, Costa AC, Castro T, Nogueira FS, Moreira MA, Luvizotto MC, Palatnik M, Palatnik-deSousa CB: Immunotherapy with the saponin enriched-Leishmune vaccine versus immunochemotherapy in dogs with natural canine visceral leishmaniasis. Vaccine 2010, 28:597-603.

5. Palatnik-de-Sousa CB: Vaccines for leishmaniasis in the fore coming 25 years. Vaccine 2008, 26:1709-1724.

6. Bradley DJ, Kirkley J: Regulation of Leishmania populations within the host. I. the variable course of Leishmania donovani infections in mice. Clin Exp Immunol 1977, 30:119-129.

7. Sanchez-Robert E, Altet L, Sanchez A, Francino O: Polymorphism of SIc11a1 (Nramp1) gene and canine leishmaniasis in a case-control study. J Hered 2005, 96:755-758.

8. Mehrotra S, Fakiola M, Mishra A, Sudarshan M, Tiwary P, Rani DS, Thangaraj K, Rai M, Sundar S, Blackwell JM: Genetic and functional evaluation of the role of DLL1 in susceptibility to visceral leishmaniasis in India. Infect Genet Evol 2012, 12:1195-1201.

9. Blackwell JM, Searle S, Mohamed H, White JK: Divalent cation transport and susceptibility to infectious and autoimmune disease: continuation of the Ity/Lsh/Bcg/Nramp1/Slc11a1 gene story. Immunol Lett 2003, 85:197-203.

10. Farouk S, Salih MA, Musa AM, Blackwell JM, Miller EN, Khalil EA, Elhassan AM, Ibrahim ME, Mohamed HS: Interleukin 10 gene polymorphisms and development of post kala-azar dermal leishmaniasis in a selected sudanese population. Public Health Genomics 2010, 13:362-367.

11. Ettinger NA, Duggal P, Braz RF, Nascimento ET, Beaty TH, Jeronimo SM, Pearson RD, Blackwell JM, Moreno L, Wilson ME: Genetic admixture in Brazilians exposed to infection with Leishmania chagasi. Ann Hum Genet 2009, 73:304-313.

12. Aliberti J, Viola JP, Vieira-de-Abreu A, Bozza PT, Sher A, Scharfstein J: Cutting edge: bradykinin induces IL-12 production by dendritic cells: a danger signal that drives Th1 polarization. J Immunol 2003, 170:5349-5353.

13. Monteiro AC, Schmitz V, Morrot A, de Arruda LB, Nagajyothi F, Granato A, Pesquero JB, Müller-Esterl W, Tanowitz HB, Scharfstein J: Bradykinin B2 Receptors of dendritic cells, acting as sensors of kinins proteolytically released by Trypanosoma cruzi, are critical for the development of protective type-1 responses. PLoS Pathog 2007, 3(11):e185.

14. Monteiro AC, Schmitz V, Svensjo E, Gazzinelli RT, Almeida IC, Todorov A, de Arruda LB, Torrecilhas AC, Pesquero JB, Morrot A, Bouskela E, Bonomo A, Lima AP, Müller-Esterl W, Scharfstein J: Cooperative activation of TLR2 and bradykinin B2 receptor is required for induction of type 1 immunity in a mouse model of subcutaneous infection by Trypanosoma cruzi. J Immunol 2006, 177:6325-6335.

15. Scharfstein J, Svensjö E: The kallikrein-kinin system in parasitic infections. Chapter 20. In Kinins. 1st edition. Edited by Bader M, De Gruyter GmbH \& Co. KG, Berlin/Boston:; 2012:321-330.

16. Monteiro AC, Scovino A, Raposo S, Gaze VM, Cruz C, Svensjö E, Narciso MS Colombo AP, Pesquero JB, Feres-Filho E, Nguyen KA, Sroka A, Potempa J, Scharfstein J: Kinin danger signals proteolytically released by gingipain induce Fimbriae-specific IFN-gamma- and IL-17-producing T cells in mice infected intramucosally with Porphyromonas gingivalis. J Immunol 2009, 183:3700-3711.

17. Svensjö E, Batista PR, Brodskyn Cl, Silva R, Lima AP, Schmitz V, Saraiva E, Pesquero JB, Mori MA, Müller-Esterl W, Scharfstein J: Interplay between parasite cysteine proteases and the host kinin system modulates microvascular leakage and macrophage infection by promastigotes of the Leishmania donovani complex. Microbes Infect 2006, 8:206-220.

18. Bradley DJ: The genetics of susceptibility and resistence in the vertebrate host. In The Leishmaniaisis, Vol. 2. 1st edition. Edited by Peters W, Killick Kendrick R. London: Academic Press; 1987:551-581.

19. Oliveira Cl, Teixiera MJ, Gomes R, Barral A, Brodskyn C: Animal models for infectious diseases caused by parasites: Leishmaniasis. Drug Discov Today 2004, 1:81-86.

20. Wilson ME, Jeronimo SM, Pearson RD: Immunopathogenesis of infection with the visceralizing Leishmania species. Microb Pathog 2005, 38:147-160

21. Sakthianandeswaren A, Foote SJ, Handman E: The role of host genetics in leishmaniasis. Trends Parasitol 2009, 25:383-391. 
22. Bradley DJ: Regulation of Leishmania populations within the host. II. genetic control of acute susceptibility of mice to Leishmania donovani infection. Clin Exp Immunol 1977, 30:130-140.

23. Ato $M$, Stäger $S$, Engwerda CR, Kaye PM: Defective CCR7 expression on dendritic cells contributes to the development of visceral leishmaniasis Nat Immunol 2002, 3:1185-1191.

24. Costa R, Motta EM, Dutra RC, Manjavachi MN, Bento AF, Malinsky FR, Pesquero JB, Calixto JB: Anti-nociceptive effect of kinin $B_{1}$ and $B_{2}$ receptor antagonists on peripheral neuropathy induced by paclitaxel in mice. $\mathrm{Br} J$ Pharmacol 2011, 164:681-693.

25. Rupniak NM, Boyce S, Webb JK, Williams AR, Carlson EJ, Hill RG, Borkowski JA, Hess JF: Effects of the bradykinin B1 receptor antagonist des-Arg9 [Leu8]bradykinin and genetic disruption of the B2 receptor on nociception in rats and mice. Pain 1997, 71:89-97.

26. Santos WR, de Lima VM, de Souza EP, Bernardo RR, Palatnik M, de Sousa Palatnik CB: Saponins, IL12 and BCG adjuvant in the FMLvaccine formulation against murine visceral leishmaniasis. Vaccine 2002, 21:30-43

27. Nico D, Claser C, Borja-Cabrera GP, Travassos LR, Palatnik M, Soares IS, Rodrigues MM, Palatnik-de-Sousa CB: Adaptive immunity against Leishmania nucleoside hydrolase maps its C-terminal domain as the target of the CD4+ T cell-driven protective response. PLoS Negl Trop Dis 2010, 4(11):e866.

28. Stober CB, Jeronimo SM, Pontes NN, Miller EN, Blackwell JM: Cytokine Responses to Novel Antigens in a Peri-Urban Population in Brazil Exposed to Leishmania infantum chagasi. AmJTrop Med Hyg 2012, Epub ahead of print.

29. Abánades DR, Arruda LV, Arruda ES, Pinto JR, Palma MS, Aquino D, Caldas AJ, Soto M, Barral A, Barral-Netto M: Immunodominant antigens of Leishmania chagasi associated with protection against human visceral leishmaniasis. PLoS Negl Trop Dis 2012, 6:e1687.

30. Palatnik-de-Sousa CB: Vaccines for canine leishmaniasis. Front Immunol 2012, 3:69

31. Plotkin SA: Correlates of protection induced by vaccination. Clin Vaccine Immunol 2010, 17:1055-1065.

32. Day MJ: Immunoglobulin $\mathrm{G}$ subclass distribution in canine leishmaniosis: a review and analysis of pitfalls in interpretation. Vet Parasitol 2007, 147:2-8.

33. Rafati S, Nakhaee A, Taheri T, Taslimi Y, Darabi H, Eravani D, Sanos S, Kaye $P$, Taghikhani M, Jamshidi S, Rad MA: Protective vaccination against experimental canine visceral leishmaniasis using a combination of DNA and protein immunization with cysteine proteinases type I and II of L. infantum. Vaccine 2005, 23:3716-3725.

34. Oliveira TM, Mineo TW, Bason M, Day MJ, Machado RZ: IgG subclass profile of serum antibodies to Leishmania chagasi in naturally infected and vaccinated dogs. Vet Parasitol 2009, 162:16-22.

35. Mauricio IL, Yeo M, Baghaei M, Doto D, Pratlong F: Towards multilocus sequence typing of the Leishmania donovani complex: resolving genotypes and haplotypes for five polymorphic metabolic enzymes (ASAT, GPI, NH1, NH2, PGD). Int J Parasitol 2006, 36:757-769.

36. Versées W, Goeminne A, Berg M, Vandemeulebroucke A, Haemers A, Augustyns K, Steyaert J: Crystal structures of T. vivax nucleoside hydrolase in complex with new potent and specific inhibitors. Biochim Biophys Acta 2009, 1794:953-960

37. Santana DM, Borja-Cabrera GP, de Paraguai Souza E, Sturm NR, de Palatnik Sousa CB, Campbell DA: Nucleoside hydrolase from Leishmania(L.) donovani is an antigen diagnostic for visceral leishmaniasis. Mol Biochem Parasitol 2002, 120:315-319.

38. Cotterell SE, Engwerda CR, Kaye PM: Enhanced hematopoietic activity accompanies parasite expansion in the spleen and bone marrow of mice infected with Leishmania donovani. Infect Immun 2000, 68:18401848.

39. Carrión J, Nieto A, Iborra S, Iniesta V, Soto M, Folqueira C, Abanades DR, Requena JM, Alonso C: Immunohistological features of visceral leishmaniasis in BALB/c mice. Parasite Immunol 2006, 28:173-183.
40. Stanley AC, Engwerda CR: Balancing immunity and pathology in visceral leishmaniasis. Immunol Cell Biol 2007, 85:138-147.

41. Palatnik-de-Sousa CB, Barbosa AF, Oliveira SM, Nico D, Bernardo RR, Santos WR, Rodrigues MM, Soares I, Borja Cabrera GP: The FML-vaccine against canine visceral leishmaniasis: from the second generation to the synthetic vaccine. Exp. Rev Vaccines 2008, 7:833-851.

doi:10.1186/1756-3305-5-261

Cite this article as: Nico et al:: Resistance to visceral leishmaniasis is severely compromised in mice deficient of bradykinin B2-receptors. Parasites \& Vectors 2012 5:261.

\section{Submit your next manuscript to BioMed Central and take full advantage of:}

- Convenient online submission

- Thorough peer review

- No space constraints or color figure charges

- Immediate publication on acceptance

- Inclusion in PubMed, CAS, Scopus and Google Scholar

- Research which is freely available for redistribution

Submit your manuscript at www.biomedcentral.com/submit
C Biomed Central 